\title{
A TENTATIVA DE COMPREENSÃO DO ESTADO MODERNO LEVANDO EM CONTA OS CONCEITOS DE POVO, SOBERANIA E DEMOCRACIA PARA JEFFERSON E ROUSSEAU.
}

\section{ATTEMPT TO UNDERSTAND THE MODERN STATE WITH THE CONCEPTS OF PEOPLE, SOVEREIGNTY AND DEMOCRACY FOR JEFFERSON AND ROUSSEAU.}

\author{
${ }^{1}$ Marcos Vinícius Viana da Silva \\ ${ }^{2}$ José Everton da Silva
}

\section{RESUMO}

A presente pesquisa estabeleceu como objetivo a análise dos conceitos de povo, soberania e democracia, fundamentadores do Estado Moderno, segundo o pensamento de Jefferson e Rousseau, autores de relevante importância histórica cultural na formação do contrato social e da democracia moderna. No tocante a hipótese, acredita-se que os conceitos apresentados por Rousseau e Jefferson são diversos, devido a sua formação histórica e geográfica bastante diferenciada. Para a realização deste artigo fora utilizado o método indutivo e da revisão bibliográfica. Como conclusão, compreendeu-se que os autores possuem, mesmo com formações diversas, mais semelhanças que divergências nos conceitos expostos.

Palavras Chave: Democracia; Jefferson, Povo; Rousseau, Soberania.

\begin{abstract}
This research has established the objective of analyzing the concepts of people, sovereignty and democracy, modern state foundations, according to the thought of Rousseau and Jefferson, authors with historical and cultural significance in the formation of the social contract and democracy. Regarding the hypothesis, it is believed that the concepts presented by Rousseau and Jefferson are diverse, due to its historical and geographical formation quite different. For the realization of this article had been used inductive and literature review method. In conclusion, it is understood that the authors have, even with diverse backgrounds, more similarities than differences in exposed concepts.
\end{abstract}

Keywords: Democracy; Jefferson; People; Rousseau; Sovereignty.

\footnotetext{
${ }^{1}$ Doutorando do Programa de Pós-Graduação Stricto Sensu em Ciência Jurídica da Universidade do Vale do Itajaí, UNIVALI - SC, (Brasil). Bolsista do Programa UNIEDU PÓS-GRADUAÇÃO, Santa Catarina - SC , (Brasil). E-mail: mvsilva0805@gmail.com

${ }^{2}$ Doutor em Ciência Jurídica pela Universidade do Vale do Itajaí, UNIVALI - SC, (Brasil). E-mail:

caminha@univali.br
} 


\section{INTRODUÇÃO}

Os elementos formadores do Estado Moderno são aqueles fatores indispensáveis para que determinada nação seja, de fato, considerada como um ente do direito internacional dotado da personalidade jurídica pertinente e de capacidade de decisão na política internacional $^{3}$.

A conceituação dos elementos formadores do Estado podem ter variadas alterações temporais e doutrinárias, isto porque, com a globalização do Estado, um conceito plenamente aplicável no século XX não necessariamente continua válido no século XXI, por inúmeros motivos.

Entretanto, em moldes gerais, a relação estatal moderna pode ser datada a partir do século XVI, quando na Itália iniciam-se as percepções de um Estado Absoluto que concentra poder. (HELLER, 1968, p.66). Ainda segundo Heller, o surgimento do Estado ocorre com base na nação organizada juridicamente.

Segundo Guimarães (2008, p.145), a nação é um espaço físico que compartilha de um determinado elemento conectivo de origem cultural, que estabelece a união entre as pessoas que vivem em um território especificado. Segundo Bobbio (2000, p.67), este elemento conectivo tem sua feição estritamente ligada ao nacionalismo, que é a característica subjetiva da nação.

Compreendendo-se assim que o Estado moderno é uma derivação dos elementos de nação e nacionalismo, criando um ente dotado de capacidade e personalidade jurídica, buscase nesta pesquisa entender seus elementos formadores, quais sejam povo e soberania, bem como a democracia que rege este Estado.

Assim, tem-se como objetivo de pesquisa, analisar e explanar sobre os elementos formadores do Estado Moderno, sendo eles povo e a soberania, bem como a democracia, com base em duas doutrinas distintas e almejando compreender, através da análise destas, a formação do Estado.

A escolha dos doutrinadores se deu devido a seus elementos de importância para a atual configuração estatal, tendo sido atribuído a Rousseau, doutrinador europeu, eminentemente genebrino, a construção de positivação do Contrato Social (juntamente com

\footnotetext{
${ }^{3}$ O Estado, personalidade originária de direito internacional público, ostenta três elementos conjugados: uma base territorial, uma comunidade humana estabelecida sobre essa área, e uma forma de governo não subordinado a qualquer autoridade exterior. (REZEK, 2008, p. 161)
} 
Locke e Hobbes) porquanto Thomas Jefferson, representa um marco na história democrática americana e mundial.

Vale ainda informar que os dois autores representam pontos de vista de momentos históricos semelhantes, uma vez que o contrato social foi redigido em meados do século XVIII enquanto os discursos de Jefferson ocorrem no final do século XVIII e início do XIX.

Relatados todos estes elementos, aduz-se que a presente pesquisa será dividida em 3 elementos, sendo trabalhado nos dois primeiros, os conceitos operacionais apresentados no título do presente artigo, porquanto no terceiro item analisar-se-á a relação entre os dois autores no tocante aos elementos estabelecidos.

Como hipótese de pesquisa, acredita-se que os elementos de democracia, povo e soberania apresentados pelos autores devem ser distintos, isto porque, apesar dos filósofos serem contemporâneos, suas origens são bastante diversas, uma vez que um deles é um doutrinador originário de uma pequena cidade localizada no centro da Europa, porquanto o outro é um político que construiu sua formação ideológica com base na independência dos Estados Unidos da América.

Referente a metodologia, será utilizado o método indutivo ${ }^{4}$, tanto para coleta dos dados quanto no tratamento dos mesmos. Já no tocante as técnicas, serão utilizadas as técnicas do Referente ${ }^{5}$, da Categoria $^{6}$, do Conceito Operacional ${ }^{7}$ e da Pesquisa Bibliográfica ${ }^{8}$.

\section{ELEMENTOS FORMADORES DO ESTADO E A DEMOCRACIA PARA JEFFERSON}

Conforme apresentados na introdução, inicia-se este estudo verificando os elementos de Povo, Soberania e Democracia para Thomas Jefferson, presidente americano que proclamou a Declaração da Independência dos Estados Unidos.

\footnotetext{
4 "MÉTODO INDUTIVO: base lógica da dinâmica da Pesquisa Científica que consiste em pesquisar e identificar as partes de um fenômeno e coleciona-las de modo a ter uma percepção ou conclusão geral". (PASOLD, 2011, p. 205).

5 "REFERENTE: explicitação prévia do motivo, objetivo e produto desejado, delimitando o alcance temático e de abordagem para uma atividade intelectual, especialmente para uma pesquisa. (...)". (PASOLD, 2011, p. 209).

6 "CATEGORIA: palavra ou expressão estratégica à elaboração e/ou à expressão de uma ideia." (PASOLD, 2011, p. 197).

7 "CONCEITO OPERACIONAL [COP]: definição estabelecida ou proposta para uma palavra ou expressão, com o propósito de que tal definição seja aceita para os efeitos das ideias expostas.” (PASOLD, 2011, p. 198).

8 "PESQUISA BIBLIOGRÁFICA: Técnica de investigação em livros, repertórios jurisprudenciais e coletâneas legais." (PASOLD, 2011, p. 207).
} 
Entretanto, antes de discutir tais elementos, vale ressaltar que Jefferson não era um doutrinador clássico, isto porque ele não teve sua biografia marcada pela elaboração de doutrinas, mas sim de uma série de discursos que servem de base para análise de seu pensamento.

Relatado isto, aduz que, para Jefferson, povo é um elemento fundamental ao Estado, “O Estado existe para servir ao povo e não o povo para servir ao Estado" (Peterson, 2012, p. 242.)

O povo se revela de tamanha importância para Jefferson que atribuía a este elemento um papel preeminente na constitucionalização do país, pois ao redigir o projeto de Constituição para a Virgínia (1776), propôs que essa lei suprema, após declarar caduca a realeza britânica, fosse promulgada "pela autoridade do povo". (COMPARATO, 1997, p. 211).

Outra passagem de Jefferson pode ser vista em um de seus discursos: "A Bill for new-modelling the form of Government and for establishingthe Fundamental principlesthereof in future". ${ }^{9}$

Diante destes itens, denota-se que Jefferson valorizava o elemento povo, tendo em vista sua importância para a construção da sociedade e principalmente para a aplicação das normas constitucionais, que segundo o autor, nada mais são do que elementos de fortalecimento do Estado e garantidor de direitos ao povo.

Dando continuidade a apresentação de conceitos operacionais sobre o tema, narra-se que a soberania para Jefferson possui sua formação bastante atrelada a soberania popular, que deveria ser exercida pelo povo na tomada de decisões e na divisão dos poderes.

Diferentemente dos conceitos absolutistas de que a soberania era estatal, na visão de Jefferson, a soberania era eminentemente popular e servia como um mecanismo de legitimação.

Segundo se verifica de umas das cartas elaboradas por Jefferson para Edmundo, a norma e os direitos do povo estão sempre conectados:

In free governments the rulers are the servants and the people their superiors and sovereigns. The whole body of the nation is the sovereign legislative, judiciary, and executive power for itself. The inconvenience of meeting to exercise these powers in person, and their inaptitude to exercise

\footnotetext{
${ }^{9}$ O projeto de lei para novo - modelar a forma de Governo e para estabelecer a princípios fundamentais, no futuro. (tradução livre). (Peterson, 2012, p. 242.)
} 
them, induce them to appoint special organs to declare their legislative will, to judge and to execute it. ${ }^{10}$

Entretanto, quando esta soberania popular era devidamente exercida, ela poderia valer também de força para as relações externas, cabendo a cada Estado o cuidado de suas condutas e responsabilidades.

Every nation has a right to govern itself internally under what forms it pleases, and to change these forms at its own will; and externally to transact business with other nations through whatever organ it chooses, whether that be a King, Convention, Assembly, Committee, President, or whatever it be. The only thing essential is, the will of the nation. ${ }^{11}$

Narrados estes elementos básicos sobre soberania para Jefferson, pode-se verificar que o doutrinador parte de duas análises diferentes sobre o tema, na primeira, ele observa o elemento soberania como uma exteriorização da vontade popular. Porquanto, em uma segunda fase, a soberania nada mais é do que a capacidade nacional de decisões sobre as condutas internas e externas a serem tomadas, tendo por óbvio uma ligação entre a primeira e a segunda forma de soberania.

Isto porque, aquilo que o Estado decide, nunca deve ser, ao menos na teoria de Jefferson, diverso que aquilo que o povo que vivem sob a égide estatal, considera como positivo e valido para a vinculação da nação.

Verificado estes os dois elementos inicias e vendo a relação direta entre si, e para com a formação do Estado, apresenta-se em sequência o conceito de democracia para o político Jefferson.

Antes do conceito, informa-se novamente que democracia não serve como elemento formador do Estado, pelo simples motivo de existirem Estados não democráticos, todavia, no tocante a presente pesquisa, a democracia servirá como elemento exteriorizador da vontade popular.

\footnotetext{
${ }^{10}$ Em governos livres os governantes são os servos e as pessoas os seus superiores e soberanos. Todo o corpo da nação é a, judiciário, legislativo e poder executivo soberano por si. A inconveniência da reunião de exercer esses poderes em pessoa, e sua inaptidão para exercê-los, levá-los a nomear órgãos especiais para declarar sua vontade legislativa, para julgar e para executá-la. (Tradução livre). (JEFFERSON to EDMUND, 1799)

${ }^{11}$ Cada nação tem o direito de governar a si próprio internamente sob que forma ele agrada, e para mudar essas formas em sua própria vontade; e externamente para transações comerciais com outras nações através de qualquer órgão da sua escolha, mesmo que seja um Rei, convenção, Assembléia, o Comitê, o presidente, ou o que quer que seja. A única coisa essencial é, a vontade da nação. (Tradução livre). (JEFFERSON to PINCKNEY, 1792)
} 
Nestesentido, abre-se o tema de democracia trazendo a baila uma das frases mais célebres de Jefferson: "Democracy is nothing more than mob rule, where $51 \%$ of the people may take away the rights of the other 49\%". ${ }^{12}$

Apesar da leitura apresentar um conceito bastante singelo de democracia, ela revela princípios implícitos de poder majoritário e de função unitária democrática. O princípio majoritário reflete a necessidade de uma união popular para a tomada de decisões e de uma participação massiva da sociedade, uma vez que cada decisão necessita de uma tomada de vontades coletivas.

Ressalta-se ainda que Jefferson foi considerado como um dos presidentes americanos que mais lutou por formas democráticas de representação do poder, tendo sido atribuído a ele o "título" de "the most democratic of the [Founding] fathers". ${ }^{13}$

Desta forma, pela narrativa de povo, soberania e democracia, percebe-se nitidamente a relação dos três elementos analisados nos discursos e falas de Jefferson, uma vez que o povo, principal elemento do Estado, se organiza de forma democrática através de uma soberania popular, tanto na esfera interna como externa.

Fica claro que, na visão de Jefferson, que a democracia e a soberania andam juntas, uma vez que o povo, para quem o governo elabora as normas e serve, escolhe seus representantes de forma democrática, e então, somente após a escolha do povo, e que os representantes podem tomar as decisões que vinculam o Estado na esfera interna e internacional.

\section{ELEMENTOS FORMADORES DO ESTADO E A DEMOCRACIA PARA ROUSSEAU}

De forma bastante semelhante ao que ocorrerá na esfera do primeiro item desta pesquisa, em que de forma sistemática foram apresentados os conceitos de povo, soberania e democracia para Thomas Jefferson, também assim o será em relação a Rousseau.

Destaca-se, introdutoriamente, que Jean Jacques Rousseau é um autor europeu, eminentemente genebrino, que construiu sua principal obra (O Contrato Social) e sua linha de

\footnotetext{
${ }^{12}$ A democracia não é nada mais do que a regra de multidão, onde $51 \%$ das pessoas podem levar embora os direitos do outro $49 \%$ - tradução livre. (JEFFERSON to MADISON, 1789)

${ }^{13}$ O mais democrático dos [Fundadores] país. (KAZIN, 2011, p.149).
} 
pensamento sobre um contexto bastante específico, tendo posteriormente suas ideias replicadas para as demais nações da Europa.

Estando assim informado o contexto regional em que o pensamento de Rousseau está firmado, cabe igualmente reforçar que suas obras de maior renome são datadas do século XVIII, mais precisamente os títulos "O contrato social” e "Emílio" que foram originalmente publicados no ano de 1762.

Restando evidenciado o contexto em que as obras de Rousseau foram pensadas e transcritas, inicia-se a partir deste momento a abordagem dos conceitos anteriormente definidos, tendo como o inicial deles, o povo, que para Rousseau, conforme se verificará, é o detentor do poder soberano e agente da vontade geral.

Segundo Rousseau, o Estado tem como elemento formador o povo, conjunto de pessoas que são regidas pelo contrato social, e governadas pela égide de uma vontade coletiva, em que cada cidadão sede um pouco de sua soberania para o Estado e este, em contra partida, protege o cidadão e suas propriedades. (BAALBAKI, 2005)

Pode-se analisar da obra o contrato social o seguinte fragmento (ROUSSEAU,2011, p.60):

Assim como, antes de erguer um grande edifício, o arquiteto observa e sonda o solo para verificar se sustentará o peso da construção, o instituidor sábio não começa por redigir leis boas em si mesmas, mas antes examina se o ovo a que se destinam mostra-se apto a recebê-las.

Assim, o povo não é apenas uma parte do processo de governabilidade, mas sim o principal elemento na esfera estatal, isto porque é ele que cria ou origina a norma, e é para com ele que a norma será aplicada.

É de se destacar que a própria elaboração do contrato social ocorre para justificar a capacidade do Estado de impor regramento para o povo, conforme aduz o próprio Rousseau. "Achar uma forma de sociedade que defenda e proteja com toda a força comum a pessoa e os bens de cada sócio, e pela qual, unido - se cada um a todos, não obedeça, todavia senão a si mesmo e fique tão livre como antes" (ROUSSEAU, 2011, p.16).

Além do caráter impositivo do contra para com o povo, ainda vale destacar que, segundo os dizeres de Rousseau, a norma jurídica garante as relações pacíficas entre os cidadãos de determinado Estado.

Esta afirmativa se baseia na dualidade que existia antes da criação do Contrato, uma vez que "o homem não detém poder natural sobre seus iguais, partindo da premissa que a 
força não produz direito", assim, sem uma norma para o povo, os conflitos de poder físico acabariam por governar as populações. (ROUSSEAU, 2011, p.21).

De forma complementar ao que foi apontado, Baalbaki afirma que os indivíduos para Rousseau se dividem e dois tipos, quais sejam: "a de citoyen isto é, cidadão ativo que participa da formação da vontade comum e a de sujet, vale dizer, alguém submetido à vontade do Estado". (BAALBAKI, 2005).

Desta forma, e pelas ponderações feitas, o povo, para Rousseau, é o titular do poder democrático, o formador da norma jurídica, e por consequência subscritor do contrato social. Isto implica a ela não apenas aceitar passivamente as determinações estatais, mas sim, e principalmente, de zelar pela vontade geral. ${ }^{14}$

Vencido o primeiro elemento observado na pesquisa no campo do filósofo de Genebra, parte-se em sequência ao debate de soberania, item fundamental para a existência e consolidação do Estado.

Pondera-se vestibularmente, que a existência da soberania de Rousseau está calcada em conceitos diversos da temática atual, isto porque hoje a soberania encontra-se baseada na imposição normativa interna e não submissão normativa internacional.

Este conceito mais moderno de soberania apresenta maior conexão com a temática atual, principalmente no tocante a impossibilidade de decisão normativa no campo do direito internacional público depois da década de 1950, com o fim da segunda guerra mundial.

Através da leitura das obras de Rousseau, pode-se com compreender que o conceito de soberania se baseia no elemento povo e, principalmente, na relação estabelecida dentro do contrato social. Segundo o Contrato Social, "Todo o discurso em torno da origem convencional do contrato encontra seu ponto culminante no conceito de soberania. (ROUSSEAU,1978, p. 48)

Assim, a soberania, refletida neste caso em um conceito mais nacional, é representada pelo exercício da vontade geral, sendo esta a vontade do corpo do povo e tendendo sempre ao bem comum.

Rousseau inclusive aponta em sua obra que a vontade geral, a vontade média da coletividade, não pode errar, isto porque ela não reflete simplesmente a vontade de uma

\footnotetext{
${ }^{14}$ A vontade geral é aquilo que anima os contratantes no sentido de movê-los na mesma direção, ou seja, no sentido positivo ao conjunto da sociedade, pois ela dirige o Estado, tornando a sociedade soberana e legítima. (CARVALHO, 2014, p. 2)
} 
maioria $^{15}$ sobre uma minoria, mas sim a vontade de uma coletividade, tendo sido ponderado aquilo que é melhor para todos.

Nestes termos a soberania é a aplicação do contrato social sobre a coletividade, não a vontade de um particular ou de um ato de magistratura, mas sim o desejo coletivo refletido em uma norma. (ROUSSEAU,1978. p. 48)

A soberania se caracteriza tão logo na capacidade estatal de converter a vontade geral em normativa, aplicando-a a todos que estão sob a tutela do Estado, quer desejem ou não as normas.

Observa-se assim a capacidade coercitiva da soberania na esfera interna, mas sem que isto retire a liberdade do indivíduo, "assim como a natureza dá a cada homem poder absoluto sobre todos os seus membros, o pacto social dá ao corpo político um poder absoluto sobre todos os seus [...]" (ROUSSEAU,1978, p.48)

Desta feita, a vontade geral, portanto, em momento algum nega o indivíduo e sua liberdade. Agindo de acordo com a vontade geral, cada indivíduo se reconhece como membro da coletividade e, enquanto cidadão, visa sempre ao interesse comum. (ANTUNES, 2006, p. 77)

Assim, soberania e povo estão nitidamente interligados, isto porque, segundo Rousseau, o povo é o detentor da vontade geral, e ao transferi-la ao contrato social, estabelece a criação do Estado e junto a ele a soberania.

O terceiro elemento fundamente da presente pesquisa, caracteriza-se pela democracia, e seus desdobramentos dentro de um sistema soberano e com povo definido.

Antes de se aprofundar nos conceitos e na importância da democracia para Rousseau, é imperioso enfatizar que o período em que a obra foi escrita era marcado por uma monarquia absolutista nos países da Europa.

O governo absoluto que havia sucedido o sistema feudal, e que governa as nações de maneira centralizada, tinha como grande característica a falta de elementos democráticos. Outrossim, o próprio contexto local de Rousseau concedeu ao autor uma experiência bastante impar no tocante as decisões sociais. (ROUSSEAU, 2011, p.26).

\footnotetext{
${ }^{15}$ Muitas vezes há uma grande diferença entre a vontade de todos e a vontade geral. Esta só diz respeito ao interesse comum, a outra diz respeito ao interesse privado, não sendo mais do que a vontade dos particulares. Mas tirem dessas mesmas vontades o mais e o menos que se anulam, e o conjunto das diferenças será a vontade geral. (ROUSSEAU, 2011, p. 30)
} 
Diretamente relacionado a condição Suíça de Genebra, é necessário observar que a cidade era pequena e dotada de poucas famílias, o que auxiliava na tomada de decisões. Tal divisão física e de demanda social ajudou a formar o conceito de democracia para Rousseau.

Introduzidos estes elementos, considera-se que o povo, titular do poder soberano, é o competente para redigir suas normas e criar o contrato social sob o qual vive. Nesta senda, para Rousseau, é totalmente inválido qualquer sistema de decisão nacional que não seja pela democracia, e não qualquer tipo de democracia, mas sim a democracia direta.

Para o filósofo, é condição de existência do sistema democrático a igualdade entre os indivíduos, "Considerando que todos precisam estar em condições de igualdade para haver democracia, nenhum ser humano poderá ser autoridade diante dos demais e as convenções." (ROUSSEAU,1978, p.68)

Este primeiro conceito apresentado já evidencia a necessidade de substituição do absolutismo pelo sistema democrático em todos os lugares. Isto porque se todos são iguais, e detentores do poder soberano, não é possível que um indivíduo, por ligação divina ou não, detenha o controle da vida de todos os outros.

Esclarecida a necessidade do sistema democrático, faz-se importante informar que Rousseau defendia a democracia em sua forma direta, isto porque para o autor, a cessão dos direitos de soberania não poderia acontecer. Assim, um sistema de representação não espelhava uma sociedade em que a soberania é dividida por todos.

Segundo Vieira e Mendes (2009, p.08):

O interesse de um representante sempre é privado e não poderá expressar o que os outros têm a dizer. Rousseau refere-se à representatividade como uma ideia absurda, originária da sociedade civil corrompida, não podendo haver democracia se essa não for direta e as leis que não forem ratificadas pelo próprio povo são consideradas nulas.

Este conceito de necessidade de uma democracia direta é fundamental para Rousseau, e pode ser explicada pela origem do pensamento em uma cidade pequena, em que a democracia poderia funcionar de forma direta.

A importância da democracia direta é tão evidente para o autor, que ao relatá-la, ele informa que o poder executivo poderia ser transferido ou outorgado por meio dos representantes, todavia, o legislativo, que representa a criação da norma, nunca poderia ser repassado. 
Nesse sentido podemos dizer que o poder legislativo tem uma função superior à do poder executivo e, quanto ao primeiro, não pode haver transferência deste poder do soberano para qualquer tipo de representante.

Devemos enfatizar que tal poder não pode ser representado pelo mesmo motivo pelo qual a vontade geral não o pode: o ato de querer não é representável. Ninguém pode querer pelo outro, muito menos por todo um povo. Quanto ao poder executivo, este sim pode ser exercido por funcionários designados pelo povo. (GOMES, 2006, p. 47)

A delegação da titularidade do poder soberano ocorre, segundo Rousseau, pela falta de vontade do povo em participar das decisões. Logo que o serviço público deixa de ser a principal ocupação dos cidadãos, e estes preferem seu interesse, o Estado se aproxima da sua ruína.

Relatados estes elementos, povo, soberania e democracia estão intimamente ligadas para o filósofo genebrino, uma vez que o povo, através da vontade geral, representa a soberania, somente ele pode decidir aquilo que é melhor para a sociedade, por meio de uma democracia, que deve ser no campo do legislativo, de forma direta.

Vencidos os pressupostos que se buscava verificar, caberá no terceiro item da pesquisa comparar os dois autores previamente selecionados, a fim de compreender e comprar a hipótese exposto, delimitando quais as divergências em semelhanças nos pensamentos doutrinários.

\section{SEMELHANÇAS E DIVERGÊNCIAS NOS CONCEITOS PESQUISADOS ENTRE JEFFERSON E ROUSSEAU, UMA FORMA DE COMPREENDER O ESTADO MODERNO.}

Tendo ocorrido a pesquisa objetivada neste trabalho, analisou-se separadamente o pensamento de Thomas Jefferson sobre três elementos, e em sequência, os mesmos elementos sobre a visão Rousseau.

No início da pesquisa, já se havia informado a diferença de localidade onde as ideias e conceitos foram concebidos, bem como a semelhança na temporalidade. Outrossim, é relevante reiterar, que os dois pensadores analisados se diferenciam muito no campo do momento pessoal em que idealizaram seus pensamentos.

Se de um lado Jefferson era renomado político americano, do outro, Rousseau era um filósofo genebrino e que passou boa parte da sua vida dedicando-se a elaboração e difusão de 
suas obras. Esta diferença de pensamento acaba por refletir, de certa forma, em suas escritas ou falas.

Dos três elementos analisados, debate-se primeiramente o povo. Este item possui fundamental importância para ambos os autores, que atribuem ao povo o elemento mais importante do Estado, e para quem o próprio Estado deve se organizar e prover mecanismos de subsistência.

Mesmo que os autores não relatem da mesma forma o povo, é nítido que este é o detentor do direito democrático (narrado em Rousseau como o Contrato Social, e em Jefferson como a Constituição). ${ }^{16}$

Dito isto, de forma geral, em relação ao primeiro elemento, tanto o pensamento americano do século XVIII como o europeu se assemelham.

Em relação ao quesito soberania, os dois autores não chegam a divergir, porém, o pensamento de Jefferson é mais amplo do que o e Rousseau. Isto fica evidente na dupla capacidade que a soberania tem para o político americano.

Segundo se aduz das leituras feitas, bem como das transcrições apresentadas, para Jefferson a soberania não se aplica apenas na esfera interna, mas também na esfera internacional, não permitindo assim a superposição de um país sobre outro.

No mesmo tema, no tocante ao pensamento de Rousseau, o que se nota é preocupação bastante elevada no tocante a esfera nacional da soberania, sendo exercida pela elaboração do contrato social, e tendo como titular o povo.

Uma possível resposta para esta divergência entre os autores, pode ser explicada pelo contexto local em que os pensamentos ocorreram. Se de um lado o americano vivia em um Estado recém liberto, que havia passado boa parte de sua existência sob o domínio de uma outra nação. A realidade de Genebra era bastante diversa, uma vez que a cidade suíça, mesmo que contextualizada em um período pós feudal de divisão de poder, vivenciava ao século XVIII uma problematização muito mais interna do que internacional.

Assim, nítido o porquê da maior preocupação de Jefferson com a realidade internacional. Seu país encontrava-se vivendo uma recente independência, enquanto na

\footnotetext{
16 Thomas Jefferson (Shadwell, 13 de abril de 1743 - Charlottesville, 4 de julho de 1826), foi o terceiro presidente dos Estados Unidos (1801-1809), e o principal autor da declaração de independência (1776) daquele país. (TUCKER e HENDRICKSON,1990)
} 
Europa, apesar de todas as guerras e conflitos por espaços, o poder e a dinâmica estatal eram outros. $^{17}$

Derradeiramente, no tocante ao terceiro item, apresenta-se a maior distinção entre os dois autores trabalhados, isto porque em um dos poucos discursos em que Jefferson tratou de democracia, ele demonstra claramente que esta forma de escolha popular se dava pela vontade da maioria dos envolvidos.

Em outras palavras, não existe aqui uma supressão do direito da minoria, mas é a maioria da população que estabelece os preceitos das normas e das relações sociais que serão tomadas.

A democracia para Rousseau revela-se um conceito muito mais complexo, alicerçado na ideia de vontade geral, que segundo o próprio autor é bastante diversa da vontade da maioria.

Assim, se para Rousseau aquilo que deve ser decidido conta ao mesmo tempo com o desejo de todos, da maioria dos desejos, mas também com a ponderação do desejo da minoria. Na figura de Jefferson, a minoria vê sua capacidade decisória diminuída pela força da maioria.

Novamente pode-se socorrer da diferença geográfica e política dos dois autores para compreender suas ponderações. Se para Jefferson a democracia ocorria em larga escala, para Rousseau ela tinha um caráter muito mais familiar ou comunitário. ${ }^{18}$

Isto representa a possibilidade de todas as decisões ponderarem vontades das minorias e maiorias, em um sistema de democracia direta. Já nos casos em que representantes são eleitos, em uma democracia indireta, é a vontade da maioria, que acaba por direcionar as condutas estatais.

Logo, por todo o exposto nestes três itens analisados, pode-se verificar que Rousseau e Jefferson, apesar das diferenças geográficas, possuem similitudes em suas compreensões do Estado e como ele interage com o cidadão que habita determinada nação. Bem como ocorre a comunhão de pensamento no caráter soberano e democrático, de forma geral.

17 A Guerra de Independência dos Estados Unidos, Guerra Revolucionária Americana (1775-1783), Guerra Americana da Independência, ou simplesmente Guerra Revolucionária nos Estados Unidos, teve início como uma guerra entre o Reino da Grã-Bretanha e as Treze Colônias, mas, de forma gradual, cresceu para uma guerra mundial entre os britânicos de um lado, e os recém-formados Estados Unidos, França, Países Baixos, Espanha, e o Reino de Mysore do outro. O resultado principal do conflito foi a vitória americana e o reconhecimento europeu da independência dos Estados Unidos, com diferentes resultados para as outras potências. (BRAUDEL,2014, p. 289).

${ }^{18}$ Segundo informaçõe históricas, a cidade de genebra no ano de 1700 contava com apenas 17.500 pessoas, que podriam ainda ser dividas entre famílias de alto renome. (BRAUDEL, 2014) 
Todavia, quando se observa uma relação mais inerente a espaços com contingente populacional muito elevado, resta claro que as políticas de Rousseau poderiam ser ineficientes no caso Americano, isto porque a quantidade de pessoas sob o qual recai a democracia é elemento fundamental para seus desdobramentos.

De outra feita, em caso oposto, a democracia representativa em pequenos espaços, com pessoas que se conhecem e que possuem laços de parentesco ou afinidade, também é equivocado, uma vez que na democracia em pequena escala, torna-se impossível a governança sem a ponderação de todos os interesses envolvidos, não importando apenas o interesse da maioria.

\section{CONCLUSÃO}


Com tudo que fora relatado, vários pontos foram observados, buscando-se durante toda a pesquisa uma análise comparativa dos elementos povo e soberania, componentes da figura estatal, bem como da democracia para Jean Jaques Rousseau e Thomas Jefferson.

Para tanto, iniciou-se o presente estudo abordando os itens acima transcritos na visão de Thomas Jefferson, relatando que tal pensador possui um contexto bastante político dentro do senário americano e que teve extrema importância para a independência dos Estados Unidos.

Estabelecido os elementos para o primeiro pensador, que se envolveu diretamente com a política, a pesquisa passou a abordar os mesmos itens na visão de Rousseau, teve sua formação voltada a gerar movimentos revolucionários, muito mais do que ele próprio revolucionou.

Evidenciados os itens na visão dos dois pensadores, este artigo verificou os elementos de similitude e divergência entre eles. Podendo compreender que existem mais semelhanças do que divergência entre os pensamentos, principalmente no tocante aos conceitos de Soberania e Povo.

Diante destes elementos, é possível compreender que a hipótese inicialmente levantada não restou comprovada, isto porque as diferenças regionais e temporais dos dois autores não foi suficiente para uma disparidade muito elevada nos conceitos e itens pesquisados neste estudo.

Ressalva-se claramente a relação de democracia entre os autores, pelos motivos anteriormente expostos, dos quais vale destacar nesta conclusão o pensamento de Jefferson em uma democracia representativa, porquanto Rousseau apenas considerava como democrático o Estado dotado de uma relação de democracia direita.

\section{REFERÊNCIA DAS FONTES CITADAS}


ANTUNES, Vanderlei Lemos. O Conceito de Soberania em Jean-Jacques Rousseau. Controvérsia - v.2, n.1, p. $70-77$ (jan-jun 2006).

BAALBAKI, Sérgio. O Estado, o povo e a soberania. Revista Jus Navigandi, Teresina, ano 10, n. 759, 2ago.2005. Disponível em: <https://jus.com.br/artigos/7045>. Acesso em: 3 mar. 2016.

BOBBIO, Norberto; MATTEUCCI, Nicola; PASQUINO, Gianfranco. Dicionário de Política. 5. ed. 2. Vol. Brasília: Universidade de Brasília, 2000.

BRAUDEL, Fernand. Escritos sobre a história. 3. ed. São Paulo, SP: Perspectiva, 2014.

CARVALHO, Manoel Jarbas Vasconcelos. Rousseau e o conceito de vontade geral: princípio metafísico ou pacto social? Ceará: RevistaHelius, ano 1, n.01, p.1-14,Cf. The Portable Jefferson, edited by Merrill D. Peterson, Penguin Books, p. 242

COMPARATO, Fábio Konder. Variações sobre o conceito de povo no regime democrático. Estud. av. [online]. 1997, vol.11, n.31, pp. 211-222.

GOMES, Fernanda da Silva. Rousseau - democracia e representação. Dissertação (Mestrado em Ética e Filosofia Política). Programa de Pós-Graduação em Filosofia. Universidade Federal de Santa Catarina, Florianópolis, 2006.

GUIMARÃES, Samuel Pinheiro. Nação, nacionalismo, Estado. Estudos Avançados, São Paulo, v. 62, n. 22, p.145-159, mar. 2008. Disponível em: <http://www.scielo.br/pdf/ea/v22n62/a10v2262.pdf>. Acesso em: 17 ago. 2015.

HELLER, Hermann. Teoria do Estado. Editora Mestre JOU: São Paulo, 1968. Jefferson letter to James Madison, September 6, 1789.

Michael Kazin, et al. eds. The Concise Princeton Encyclopedia of American Political History (2011).

PASOLD, Cesar Luiz. Metodologia da Pesquisa Jurídica: Teoria e Prática. $12^{\mathrm{a}}$ Edição revisada. São Paulo: Conceito Editorial, 2011.

REZEK, Francisco. Direito Internacional Público: Curso Complementar. 11. Ed. São Paulo: Saraiva, 2008,

Robert W. Tucker e David C. Hendrickson. Empire of Liberty: The Statecraft of Thomas Jefferson.1990.

ROUSSEAU, J.-J. Do contrato social. 2ª ed. São Paulo: Abril Cultural 1978.

ROUSSEAU, Jean Jaques. Do contrato social ou princípios do direito político. Tradução Eduardo Brandão, Organização e introdução Maurice Graston. São Paulo: Pinguin Classics Companhia das Letras, 2011. 
Thomas Jefferson to Edmund Randolph, 1799. ME 10:126 Thomas Jefferson to Thomas Pinckney, 1792. ME 9:7

VIEIRA, Rejane Esthe e MENDES, Betina Souza. Democracia segundo Rousseau: uma análise histórica sobre as principais ideias de rousseau na obra 'o contrato social' e sua contribuição para democracia na contemporaneidade. Revista Direitos Fundamentais e Democracia. ISSN 1982-0496. Vol. 5 (2009). 